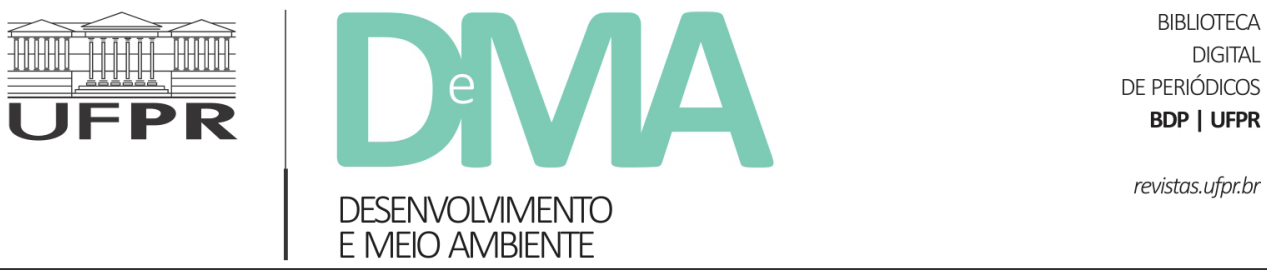

\title{
Governança da restauração florestal da paisagem no Brasil: desafios e oportunidades
}

\section{Governance of forest landscape restoration in Brazil: challenges and opportunities}

\author{
Cristina ADAMS ${ }^{1 *}$, Luciana Gomes de ARAUJO ${ }^{1}$, Rosely Alvim SANCHES ${ }^{1}$, Célia Regina Tomiko \\ FUTEMMA $^{2}$, Jordano Roma BUZATI ${ }^{1}$, Vitor Hirata SANCHES ${ }^{1}$, Gabriela Silva Santa Rosa MACEDO ${ }^{2}$ \\ ${ }^{1}$ Universidade de São Paulo (USP), São Paulo, SP, Brasil. \\ ${ }^{2}$ Universidade Estadual de Campinas (Unicamp), Campinas, SP, Brasil. \\ *E-mail de contato: cadams@usp.br
}

Artigo recebido em 11 de dezembro de 2020, versão final aceita em 3 de maio de 2021, publicado em 12 de novembro de 2021.

RESUMO: $\quad$ O Brasil ocupa um papel importante em diversos acordos e compromissos globais das agendas de conservação florestal e climática. A implementação desses acordos e o avanço dos debates em torno deles expõem a necessidade de desenvolvimento de arranjos de governança em diversas áreas, dentre elas a Restauração Florestal da Paisagem. Espera-se que a governança da Restauração Florestal da Paisagem produza resultados positivos no comprometimento de seus atores sociais, no desenvolvimento de instrumentos de gestão e no ganho de escala (upscale) dos projetos e programas nas diferentes paisagens e biomas do país. Nesse contexto, este estudo tem como objetivo traçar o estado de conhecimento dos modelos conceituais de governança da Restauração Florestal da Paisagem, por meio de uma revisão sistemática da literatura acadêmica mundial, contribuindo para a organização de um arcabouço teórico-conceitual aplicado aos sistemas de governança da Restauração Florestal da Paisagem do Brasil, representados por projetos, programas e redes de trabalho. Os resultados mostram, por um lado, que há uma diversidade de modelos de governança colaborativa em desenvolvimento em algumas iniciativas brasileiras de Restauração Florestal da Paisagem, principalmente na Mata Atlântica e na Amazônia. Por outro lado, há ainda uma grande lacuna na produção de pesquisa com enfoque específico de análise da governança da Restauração Florestal da Paisagem, que contribua para a construção de redes de aprendizados e evolução dos modelos de governança em desenvolvimento no Brasil.

Palavras-chave: modelos de governança; restauração florestal da paisagem; rede de múltiplos atores sociais; escalas múltiplas. 
ABSTRACT: Brazil plays a significant role in distinguished global agreements on forest conservation and climate change. The implementation of these agreements requires governance arrangements in several fields, such as Forest Landscape Restoration (FLR). It is expected that FLR governance systems generate positive results in the commitment of social actors, development of management tools, and upscaling of projects and programs in the different landscapes and biomes in the country. In this context, this study aims to trace the state of knowledge of conceptual models of governance of Forest Landscape Restoration, using a systematic review of the international literature to organize a theoretical-conceptual framework applied to FLR governance systems in Brazil. The results show that Forest Landscape Restoration initiatives based on collaborative governance exist in Brazil, mainly in the Atlantic Forest and the Amazon. However, there is still a gap in research focusing specifically on FLR governance beyond case studies. The advancement of this research field can contribute to the improvement of social learning in FLR networks and governance models under development in Brazil.

Keywords: governance models; forest landscape restoration; social networks; multiple scales.

\section{Introdução}

A restauração florestal vem ganhando espaço na agenda ambiental internacional nos últimos anos, como uma forma de mitigar os impactos causados pelo desmatamento e a degradação dos ecossistemas que acompanham as frentes de desenvolvimento econômico na maioria dos países. As iniciativas de reflorestamento têm buscado restaurar bacias hidrográficas e áreas produtivas degradadas, controlar processos de desertificação, restaurar a biodiversidade, mitigar as mudanças climáticas e produzir serviços ecossistêmicos (van Oosten, 2013; Locatelli et al., 2015). A governança global da restauração florestal vem seguindo a mesma trajetória da governança ambiental, de modelos mais hierárquicos e centralizados para sistemas de gestão comunitária (Skutsch \& Turnhout, 2018; Reyes-García et al., 2019) e cogestão, os quais envolvem um número maior de atores públicos e privados (Pistorius \& Freiberg, 2014; Butler et al., 2015; Diver, 2016).

Durante as décadas de 1980 e 1990, os modelos de governança ambiental assumiram a im- plementação de metas de acordos internacionais, a partir do Estado, para que se desdobrassem em políticas públicas nacionais e regionais (Pistorius \& Freiberg, 2014). Neste contexto, uma série de iniciativas lideradas pela Organização das Nações Unidas (ONU), como a Convenção para a Diversidade Biológica (CDB), a Convenção-Quadro das Nações Unidas sobre Mudanças Climáticas (UNFCCC), e a Convenção das Nações Unidas para o Combate à Desertificação e Mitigação dos Efeitos das Secas (UNCCD), contribuíram para o fortalecimento da agenda da conservação ambiental, com desdobramentos na restauração florestal e recuperação de áreas degradadas (Mansourian, 2017; Cameron, 2018).

Em 2010, as metas 14 e 15 do Plano Estratégico para a Biodiversidade da CDB (Metas de Aichi para 2020) ligaram a restauração florestal ao fornecimento de serviços ecossistêmicos e à redução da pobreza, com previsão de restaurar ao menos $15 \%$ de todos os ecossistemas degradados, com enfoque nas florestas (Pistorius \& Freiberg, 2014). No mesmo ano, a UNFCCC criou o Fundo Verde para o Clima, que passou a financiar um número 
crescente de projetos de restauração florestal (Cameron, 2018). Nesse momento, iniciativas como o REDD+ (Redução de Emissões de Gases de Efeito Estufa Provenientes do Desmatamento e da Degradação Florestal) também passaram a contribuir para a restauração em larga escala, em diversas regiões do planeta (Alexander et al., 2011). Em 2011, na reunião do Global Partnership on Forest Landscape Restoration (GPFLR), a UNFCC e a União Internacional para a Conservação da Natureza (IUCN) lançaram, em conjunto com o governo alemão, o Bonn Challenge, com a meta global de restaurar 150 milhões de hectares de áreas degradadas e desmatadas até 2020. Esta meta foi aumentada para 350 milhões de hectares até 2030 pela Declaração de Florestas de Nova Iorque (Aronson \& Alexandre, 2013; Mansourian, 2016; Cameron, 2018). Em 2013, na $19^{\text {a }}$ Conferência das Partes da UNFCCC (COP19), o Banco Mundial lançou o Fundo BioCarbon para financiar paisagens florestais, em que Noruega, Reino Unido e EUA assumiram o compromisso de contribuir com 280 milhões de dólares (Banco Mundial, 2013; Cameron, 2018). Em 2014, países da América Latina e do Caribe lideraram o lançamento da Iniciativa 20x20 na $20^{a}$ Conferência da Partes (COP20), com o objetivo de restaurar 20 milhões de hectares até 2020.

$\mathrm{O}$ governo brasileiro aderiu à Iniciativa 20×20 e, em 2015, na 21 a Conferência da Partes (COP21) realizada em Paris, o país aprovou sua Contribuição Nacionalmente Determinada (NDC), comprometendo-se a restaurar 12 milhões de hectares da Mata Atlântica, no total de 15 milhões de hectares restaurados até 2030. Em 2018, a Plataforma Intergovernamental para a Biodiversidade e Serviços Ecossistêmicos (IPBES) lançou o relatório do primeiro levantamento global sobre degradação e restauração florestal, reforçando a importância de se reduzirem e reverterem processos de degradação dos ecossistemas, destacando a importância das abordagens em escala ${ }^{1}$ de paisagem para o cumprimento de agendas integradas de desenvolvimento, agricultura, florestas, energia, água e infraestrutura (IPBES, 2018).

$\mathrm{O}$ avanço desses acordos e dos debates em torno deles expõe os desafios de governança para o desenvolvimento de políticas e instituições capazes de influenciar positivamente a restauração florestal (Mansourian, 2016; 2017). Nesse sentido, novos modelos de governança vêm sendo desenvolvidos, os quais atribuem um papel mais importante a atores não governamentais, incluindo parcerias público-privadas, mecanismos de mercado e financeiros (REDD, Pagamento por Serviços Ambientais - PSA e Certificação) e redes de trabalho (Melo et al., 2013; Pistorius \& Freiberg, 2014).

Nesse cenário, a abordagem da Restauração Florestal da Paisagem (RFP) vem ganhando espaço político, promovida por organizações como a Organização das Nações Unidas para a Alimentação e a Agricultura (FAO), a IUCN, o Fundo Mundial para a Natureza (WWF) e o World Resources Institute (WRI), junto com governos de diversos países (Maginnis \& Jackson 2002), incluindo o Brasil. O termo Restauração Florestal da Paisagem (RFP) foi cunhado em 2000 (Mansourian, 2017) e é definido

\footnotetext{
${ }^{1}$ Por escala, entende-se a dimensão espacial, temporal ou jurisdicional (entre outras), quantitativa, ou analítica, para mensurar e estudar qualquer fenômeno ou objeto (Gibson et al., 2000). Muitas vezes utilizada como sinônimo de nível, o qual Gibson et al. (2000) define como sendo a posição dentro de uma determinada escala.
} 
como um processo de longo prazo que objetiva recuperar a funcionalidade ecológica (produção de bens, serviços e processos ecológicos) e melhorar o bem-estar humano em paisagens florestais degradadas ou desmatadas (Maginnis \& Jackson, 2002; IUCN \& WRI, 2014). O arcabouço da RFP inclui objetivos de conservação e desenvolvimento, além da dimensão espacial e temporal (Mansourian, 2016).

As metas internacionais acordadas pelo Brasil e o conceito de RFP colocam para os gestores públicos e demais atores da restauração florestal o desafio de escolher áreas-piloto para testar métodos capazes de dar escala (upscale) à restauração florestal. Esse desafio embute a geração de conhecimentos, a medição de ganho florestal, a formulação de arranjos institucionais e a tradução de lições aprendidas para a elaboração de novas políticas públicas. Esse processo de desenvolvimento da governança da RFP levanta inúmeras perguntas, dentre as quais destacamos:

(i) Quais são os modelos de governança da restauração florestal descritos na literatura?

(ii) Desses, há modelos que estão sendo desenvolvidos no Brasil?

(iii) No âmbito dos modelos de governança da RFP no Brasil, quais os desafios e as oportunidades identificados na literatura?

Este artigo busca traçar o estado de conhecimento dos modelos conceituais de governança da RFP, por meio de uma revisão da literatura acadêmica mundial, com o objetivo de contribuir para a organização de um arcabouço teórico-conceitual que possa ser aplicado aos sistemas de governança da RFP do Brasil. Discutimos algumas iniciativas brasileiras de governança com o objetivo de se analisar os desafios associados ao seu desenvolvi- mento, bem como as oportunidades atuais para a sua evolução.

A seguir, apresentamos os principais conceitos relacionados à RFP. Na próxima seção, analisamos o arcabouço teórico-conceitual que vem sendo construído sobre a governança da RFP na literatura internacional. Na terceira seção, descrevemos os métodos utilizados na revisão da literatura. Na quarta parte, são apresentados e discutidos os resultados do estado da arte da literatura sobre o tema no Brasil e, em seguida, são feitas considerações finais sobre os resultados obtidos.

\subsection{Conceitos e definições adotados}

A dificuldade inicial no levantamento e sistematização da literatura sobre a governança da restauração florestal deve-se às diferentes definições de conceitos-chave, como paisagem, restauração florestal ou RFP, e governança. Para a Ecologia da Paisagem, a paisagem abrange o seu caráter estrutural e funcional como matriz ecológica, enquanto os geógrafos incluem na paisagem o uso antrópico e seus sistemas produtivos (van Oosten 2013). Neste artigo, definimos as paisagens da restauração florestal como sistemas socioecológicos complexos (SSE), que são caraterizados pelo acoplamento dos sistemas ecológicos e sociais, com mecanismos de retroalimentação e adaptação (Folke et al., 2005; Fisher, 2018; Mansourian et al., 2019).

No que se refere ao processo de recuperar a cobertura florestal perdida em uma paisagem, diferentes conceitos são utilizados. A restauração ecológica é o processo de cuidar da recuperação de um ecossistema que tenha sido afetado, degradado ou destruído, com o objetivo de retornar à 
sua integridade ecológica, medida a partir de um modelo referencial (Chazdon et al., 2016). Reflorestamento refere-se ao restabelecimento de uma floresta nativa e/ou exótica em área recentemente desmatada, enquanto que o aflorestamento ocorre em áreas desprovidas de cobertura florestal há mais tempo (mais de 50 anos, segundo a UNFCCC). O re-greening abrange métodos de manejo no nível da propriedade, de forma a aumentar a cobertura arbórea e arbustiva como, por exemplo, em sistemas agroflorestais. A reabilitação ou remediação, normalmente, refere-se a projetos para melhorar a qualidade e as funções ecossistêmicas de áreas extremamente degradadas, como áreas de mineração, e caracterizam-se por uma recuperação apenas parcial dos seus serviços ecossistêmicos (Chazdon et al., 2016; Cameron 2018).

Já a definição de Restauração Florestal da Paisagem (RFP) é bastante ampla, incluindo não só a restauração de grandes extensões de áreas florestadas fragmentadas ou degradadas, mas também a compatibilização da restauração com outros usos da terra, compondo mosaicos que podem incluir agricultura, sistemas agroflorestais, sistemas de pousio aperfeiçoados, corredores ecológicos e Áreas de Proteção Permanente (IUCN \& WRI, 2014). A criação de paisagens multifuncionais está implícita no conceito de RFP e vem sendo apontada como o caminho para aliar conservação da biodiversidade e produção, servindo a interesses ecológicos e econômicos (van Oosten, 2013).

No que se refere ao conceito de governança, Arts \& Visseren-Hamakers (2012, p. 4) o definem como as inúmeras formas pelas quais os atores públicos e privados (do mercado ou da sociedade civil) se envolvem e lidam com questões de interesse público, de forma integrada. A capacidade de agentes sociais em estabelecer objetivos comuns, definir o compromisso de cada envolvido e constituir consensos em territórios é central para a ideia de governança (Davoudi et al., 2008). Para Mansourian (2016), a governança ocupa-se de quem toma as decisões, de como os processos decisórios se dão e quais arcabouços institucionais apoiam a implementação de tais decisões.

$\mathrm{O}$ estudo dos sistemas de governança requer que diferentes escalas sejam abordadas, dada a natureza de complexidade dos SSE. Essa abordagem justifica-se pela necessidade de se criarem instituições capazes de responder às intervenções humanas nos diversos níveis e escalas de SSE, do local ao global (Cash et al., 2006; Brondízio et al., 2009). Autores como van Butler e Goldstein (2010), van Oosten (2013) e Pistorius \& Freiberg (2014) propõem que os modelos de governança adotem uma abordagem de redes colaborativas, a qual, sob a perspectiva da complexidade, não pode ser tratada como um processo de planejamento linear, mas sim um processo dinâmico e imprevisível de negociações e trocas, com múltiplos possíveis resultados (van Oosten, 2013).

Para Brancalion et al. (2016) e Mansourian (2017), a governança da RFP é entendida como o conjunto amplo de instituições e atores sociais, e as maneiras pelas quais eles se conectam e inter-relacionam ao longo do tempo, para influenciar a implementação da restauração de uma paisagem florestal. Os desafios da RFP incluem reconciliar o bem-estar humano com a integridade ecológica; apoiar políticas públicas que facilitam a restauração; definir quem decide sobre o que restaurar, quem financia a restauração e quem se beneficia dela; e garantir o engajamento dos atores e a negociação de compromissos entre eles. Embora a importância 
da governança no sucesso de iniciativas de RFP venha sendo reconhecida na literatura (Guariguata \& Brancalion, 2014), a investigação sobre o desenvolvimento de modelos conceituais ainda está em sua infância (van Ooosten, 2013; Ros-Tonen et al., 2014; Mansourian, 2016). O debate da governança da RFP inclui a integração das múltiplas escalas de uma paisagem (e.g., sociopolítica, ecológica e demográfica); o desajuste entre instituições formuladas em um nível administrativo (municipal, estadual e nacional) e a realidade da paisagem a ser restaurada; a complexidade de se compreender a motivação de atores sociais com diferentes interesses e a adoção de uma perspectiva adaptativa de governança que entenda o seu comportamento dinâmico e de longo prazo, capaz de se redefinir em novos arranjos para que os objetivos da RFP sejam alcançados (van Ooosten, 2013; Mansourian, 2017; Fischer, 2018; Mansourian et al., 2019).

A partir do exposto acima, a paisagem da restauração florestal resulta da complexa interação entre múltiplos atores, instituições e decisões que atravessam escalas sociais, ecológicas, geográficas e políticas num processo contínuo de adaptação e aprendizagem.

\section{Construindo um modelo conceitual de Governança para a RFP}

Nesta seção, a partir da literatura acadêmica, foram organizadas as informações teóricas e conceituais sobre modelos de governança da RFP, que orientarão as análises das iniciativas de governança da RFP no Brasil (Subseção 4.2.).

O debate acadêmico sobre este tema se beneficia dos avanços trazidos pela literatura sobre a gestão de recursos naturais e bens comuns (com- mons), em que os modelos de cogestão adaptativa são apontados como uma forma promissora para lidar com as complexidades de SES (Ros-Tonen et al., 2014). Na tentativa de avançar na construção de modelos analíticos, Ros-Tonen et al. (2014) propuseram cinco princípios e três condições facilitadoras para a governança adaptativa da paisagem, a partir de uma revisão da literatura (Tabela 1).

No modelo discutido por Ros-Tonen et al. (2014), as paisagens são capazes de absorver distúrbios e se reorganizar, retendo suas funções, estruturas, identidades e mecanismos de retroalimentação. Nelas desenvolvem-se diferentes estruturas de governança, que se conectam, se integram e se complementam, sem a dominância centralizada em um ator em particular. Múltiplos atores sociais definem a dinâmica dessas estruturas, por meio de estratégias, ações e regras negociadas de forma transparente. Riscos e incertezas são assumidos em ambientes cultivados pela construção de confiança e de memória institucional, com a participação central de organizações-ponte capazes de fazer circular conhecimento de múltiplas fontes. A construção de capital social, a atuação de organizações-ponte e a garantia de recursos financeiros a longo prazo constituem elementos favoráveis ao desenvolvimento da governança adaptativa da RFP (Folke et al., 2005; Young \& Lipton, 2006; Ros-Tonen et al., 2014). Chazdon et al. (2020) listam seis princípios holísticos orientadores da essência da RFP e com enfoque em práticas locais, que se complementam aos propostos por Ros-Tonen et al. (2014). Dentre eles estão a participação social e o ajuste de metodologias aos contextos locais por meio de diversas abordagens adaptadas à realidade de cada paisagem.

Mansourian $(2016 ; 2017)$ aponta que seria difícil obter um arcabouço conceitual universal para 
TABELA 1 - Princípios e condições facilitadoras para a governança adaptativa da paisagem segundo Ros-Tonen et al. (2014).

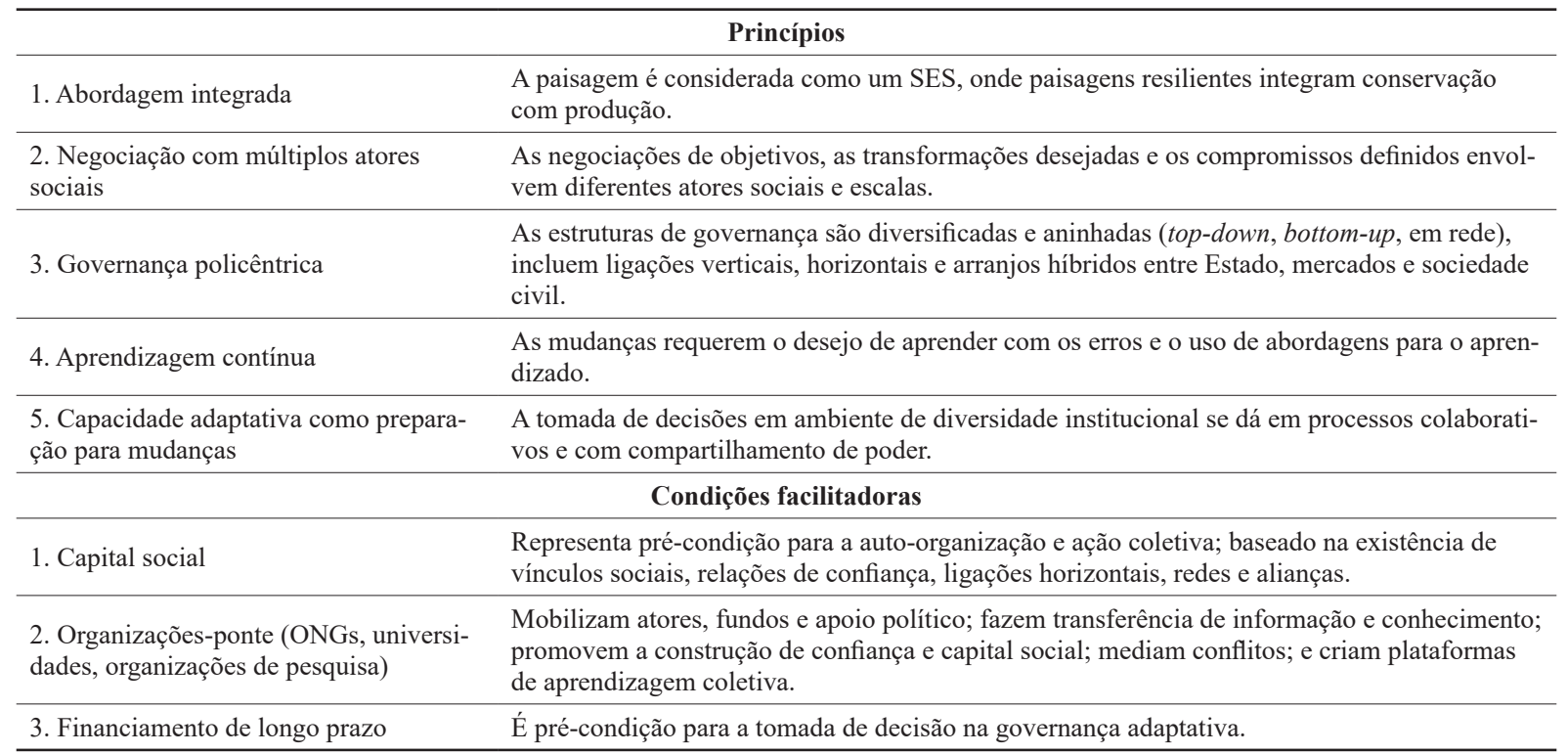

lidar com os desafios da governança da RFP, mas propõe um modelo analítico para identificar gargalos e oportunidades na implementação de iniciativas de RFP. Seu modelo está organizado em torno de três recomendações: (i) contextualizar o processo de RFP, (ii) reconfigurar a escala da governança de forma a abarcar a paisagem e (iii) mapear os atores e suas relações.

A contextualização do processo de RFP refere-se aos aspectos históricos, culturais, econômicos, políticos, bem como ecológicos, de disponibilidade de dados e conhecimento técnico sobre os ecossistemas. Essa contextualização é singular a cada paisagem da RFP. A segunda recomendação requer a elaboração de novas formas de governança capazes de conciliar as escalas político-administrativas e de paisagem, com ênfase no engajamento de atores sociais como entes corresponsáveis pela implementação da restauração. Neste modelo, é fundamental que as estruturas de governança não se associem apenas às iniciativas de restauração com durações pré-determinadas (devido ao financiamento, por ex.), mas se integrem a outros componentes institucionais da paisagem. Neste ponto, Ball et al. (2014), Ros-Tonen et al. (2014) e Mansourian (2017) concordam que a governança policêntrica (Nagendra \& Ostrom, 2012) (Tabela 1) é o melhor modelo para a RFP, já que é diversificada, flexível, redundante e reconhece as interligações entre as diferentes escalas e níveis. Nos sistemas de governança policêntrica, o Estado deixa de ser central e exerce um papel de apoiador, criando-se uma condição favorável para a participação de outros atores sociais e estimulando ações de colaboração (Long et al., 2018), portanto favorece a ampliação das possibilidades de se contemplar um número maior de interesses e objetivos da sociedade, podendo melhorar o resultado da implementação de ações de RFP (Mansourian et al., 2019) 
Por último, o entendimento do tipo e qualidade das relações que se estabelecem entre os atores sociais também é central para a governança da RFP (Ball et al., 2014; Ros-Tonen et al., 2014; Mansourian, 2017; Mansourian \& Sgard, 2019). Os atores podem ser caracterizados quanto ao seu caráter (público, privado, sociedade civil), nível de atuação (local, municipal, estadual, nacional, global), ou seu papel na RFP (financiar, estabelecer políticas públicas, prestar auxílio técnico, realizar monitoramento). Além disso, podem ser analisados pelos diferentes tipos de relações entre si, como no caso de atores oriundos de um mesmo nível e que colaboram em ligações horizontais (Seixas $\&$ Berkes, 2010), ou atores que disputam por recursos ou decisões em ligações verticais de diferentes níveis de uma escala sociopolítica (Young, 2006).

Outros autores (Agrawal et al., 2008; Le et al., 2012) procuraram sistematizar os fatores socioeconômicos, institucionais e administrativos que potencializam a possibilidade de sucesso da restauração florestal, a partir da análise de estudos de caso de diversas regiões (Tabela 2).

TABELA 2 - Fatores de sucesso da restauração florestal, segundo Agrawal et al. (2008) e Le et al. (2012).

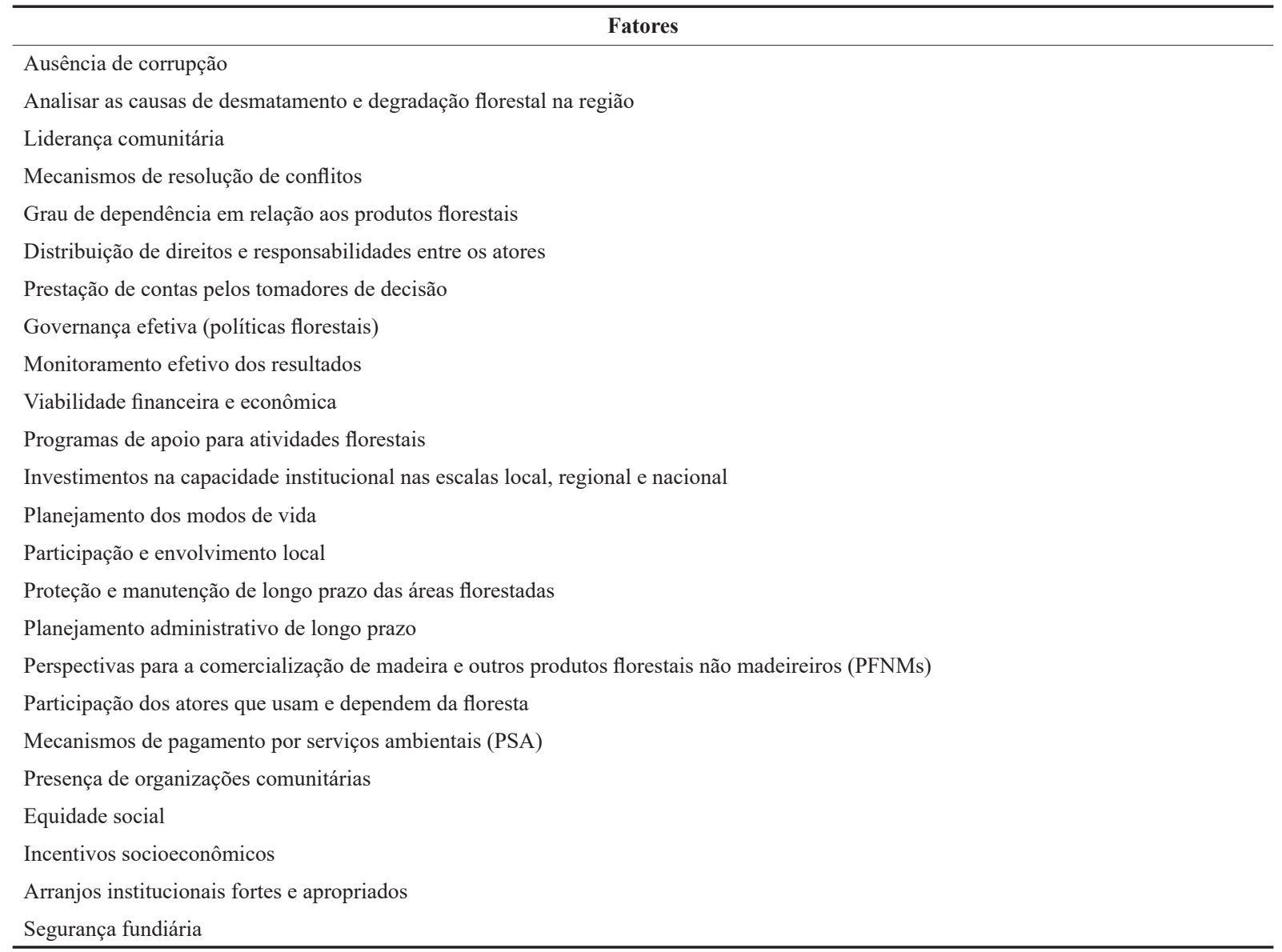


Chazdon \& Guariguata (2016) também analisaram estudos de caso ao redor do mundo e, a partir disso, sistematizaram fatores facilitadores de ações de restauração florestal em larga escala, considerando diferentes conjuntos de atores sociais (Tabela 3 ).
Usando uma abordagem processual para analisar a governança da RFP, Mansourian (2016) dividiu o processo de RFP em etapas e identificou os diferentes fatores envolvidos em cada uma delas (Tabela 4).

TABELA 3 - Fatores facilitadores da restauração florestal de larga escala segundo Chazdon \& Guariguata (2016, p. 723, adaptado de Lamb, 2014).

\begin{tabular}{|c|c|}
\hline Ator Social & Fatores facilitadores \\
\hline Governo nacional & $\begin{array}{l}\text { - Segurança aos direitos fundiários e de propriedade de pequenos produtores; } \\
\text { - Desenvolvimento de planos nacional/regionais de formas ativas e passivas de restauração florestal; } \\
\text { - Desenvolvimento de política nacional de incentivos econômicos para regeneração natural, com plantio } \\
\text { de espécies nativas, ou estratégias mistas. }\end{array}$ \\
\hline $\begin{array}{l}\text { Governo estadual ou } \\
\text { municipal }\end{array}$ & $\begin{array}{l}\text { - Desenvolvimento de ferramentas para diagnóstico e protocolos de manejo e monitoramento da } \\
\text { regeneração florestal; } \\
\text { - Capacitação de equipes de extensão florestal para diagnosticar o potencial de regeneração natural em } \\
\text { terras públicas e privadas; } \\
\text { - Treinamento de lideranças comunitárias e jovens para monitorar a restauração florestal/regeneração } \\
\text { natural; } \\
\text { - Popularização da regeneração natural como forma resiliente de reflorestamento; } \\
\text { - Valorização dos administradores públicos por ações favoráveis à regeneração natural, por meio de } \\
\text { prêmios, certificados e distinções. }\end{array}$ \\
\hline Empresas e indústrias & $\begin{array}{l}\text { - Criação de cadeias de valor para madeira e PFNMs de florestas certificadas; } \\
\text { - Promoção de preços para créditos de carbono e outros serviços ecossistêmicos de florestas } \\
\text { naturalmente regenerantes. }\end{array}$ \\
\hline Universidades & $\begin{array}{l}\text { - Treinamento de técnicos florestais em levantamentos e diagnósticos; } \\
\text { - Desenvolvimento de planos de manejo e protocolos de monitoramento de restauração florestal, com } \\
\text { proprietários rurais. }\end{array}$ \\
\hline Financeiro & - Provisão de créditos/subsídios para proprietários rurais em áreas de regeneração natural. \\
\hline
\end{tabular}

TABELA 4 - Etapas e fatores de governança da RFP segundo Mansourian (2016).

\begin{tabular}{cl}
\hline Etapas & \\
\hline Iniciar & Financiamento, políticas nacionais, práticas e costumes locais. \\
Estimular & Sanções legais e medidas coercitivas, ou iniciativas baseadas em mercado. \\
Mediar & Facilitação e negociações de processos da governança. \\
Mudar & Superação de obstáculos. \\
Compartilhar & Custos imediatos e benefícios de longo prazo, distribuídos de forma equânime entre os atores. \\
Fazer cumprir & Instituições fortes e localmente respeitadas e mecanismos de cumprimento de regras. \\
Monitorar & Mecanismos e instituições efetivos para a gestão adaptativa e monitoramento, que sejam aceitos por todos os atores. \\
\hline
\end{tabular}


Ainda no âmbito do mapeamento de condições favoráveis para o desenvolvimento da governança da RFP, Pistorius \& Freiberg (2014) apontam as condições iniciais, o desenho institucional, a liderança e a colaboração em redes com múltiplos atores como fatores importantes para os resultados da RFP. As condições iniciais se referem às relações prévias de cooperação e/ou conflito que afetam o nível de confiança dos atores da rede. O desenho institucional e a atuação de lideranças influenciam a trajetória de formação de redes de trabalho, que caminham da construção de confiança mútua para compromissos individuais e coletivos. Considerando as especificidades geográficas e ecológicas onde a RFP ocorre, com a diversidade de escalas e variações na coordenação e dinâmica de redes de trabalho, Pistorius \& Frieberg (2014) sugerem três diferentes desenhos de governança em redes: (i) descentralizado e governado pelos próprios membros (autogovernança), (ii) centralizado por uma organização líder eleita pelos membros da rede, ou (iii) centralizado, a partir da criação de uma nova instância administrativa criada para esta finalidade.

No primeiro caso, a autogovernança requer um alto grau de confiança e comprometimento quanto aos objetivos da rede. É desta forma que a maioria das redes é inicialmente formada com a vantagem conferida pela flexibilidade, que permanece enquanto a rede se mantém relativamente pequena. Um aumento no número de membros pode provocar duas situações: a manutenção de seu tamanho através de regras para associação, excluindo-se novos membros; ou uma forma mais centralizada de governança, onde a coordenação das atividades passa a ser realizada por um dos atores (segundo caso), ou uma organização criada com esta finalidade (terceiro caso) (Pistorius \& Freiberg 2014).
Os modelos descritos de forma resumida, acima, tratam a paisagem como um SSE complexo adaptativo, que requer uma abordagem cuidadosa a respeito do ajuste entre escalas e do acúmulo de experiência e conhecimento para evoluir a partir dos aprendizados. Nesta perspectiva, os diversos autores sugerem arranjos institucionais colaborativos policêntricos e em rede. Nesses arranjos, o entendimento das interações e negociações entre os atores sociais da RFPé de fundamental importância para a construção de compromissos. Esta é uma entre as diversas condições que facilitam a construção de sistemas de governança da RFP.

\section{Métodos}

A identificação e seleção da literatura foram realizadas por meio do levantamento e mapeamento sistemático (James et al., 2016), dividido em duas etapas. Na primeira, procedeu-se à busca de artigos sobre o estado da arte do conhecimento científico sobre a governança da RFP, com foco no Brasil, mas também revisões de literatura e trabalhos teóricos e conceituais. Foi dada preferência para a utilização de palavras-chave em inglês, e o nome em português só foi utilizado quando a palavra-chave se referia a um nome próprio brasileiro (p.ex., Conservador das Águas).

A busca foi realizada em artigos, teses, dissertações, livros, capítulos de livros e literatura cinza (pesquisas não publicadas ou publicações não comerciais, como relatórios de ONGs), e relatórios oficiais de órgãos governamentais. Entretanto, foi dada prioridade aos artigos publicados em periódicos científicos entre 2000-2018, através das bases de dados Scielo, Web of Science e Scopus, e a literatura cinza não foi buscada de forma sistemática. 
Foram selecionados artigos que tratassem da RFP como um dos temas principais (excluindo artigos com foco exclusivo em aspectos ecológicos da RFP), em estudos de caso no Brasil e artigos de revisão de literatura. Para tal, foram usadas as palavras-chave e combinações entre elas, em um total de 55 entradas (Tabela 5). A primeira triagem dos artigos foi organizada em um banco de dados no Mendeley.
$\mathrm{Na}$ primeira etapa, foram levantados 527 artigos e criadas tags (etiquetas) para cada artigo, indicando qual conjunto de palavras-chave levou ao resultado (em alguns casos há mais de um conjunto de tags, porque o resultado foi obtido por múltiplas buscas). Do banco de dados, foram excluídos os artigos sem relevância (por ex., exclusivamente ecológicos, restaurações em escala local), a partir da leitura do resumo, chegando-se a um total de 224

TABELA 5 - Palavras-chave utilizadas no levantamento da literatura (n=55 entradas)*, com (conector booleano "AND”) ou sem combinações entre palavras-chave 1 e 2 .

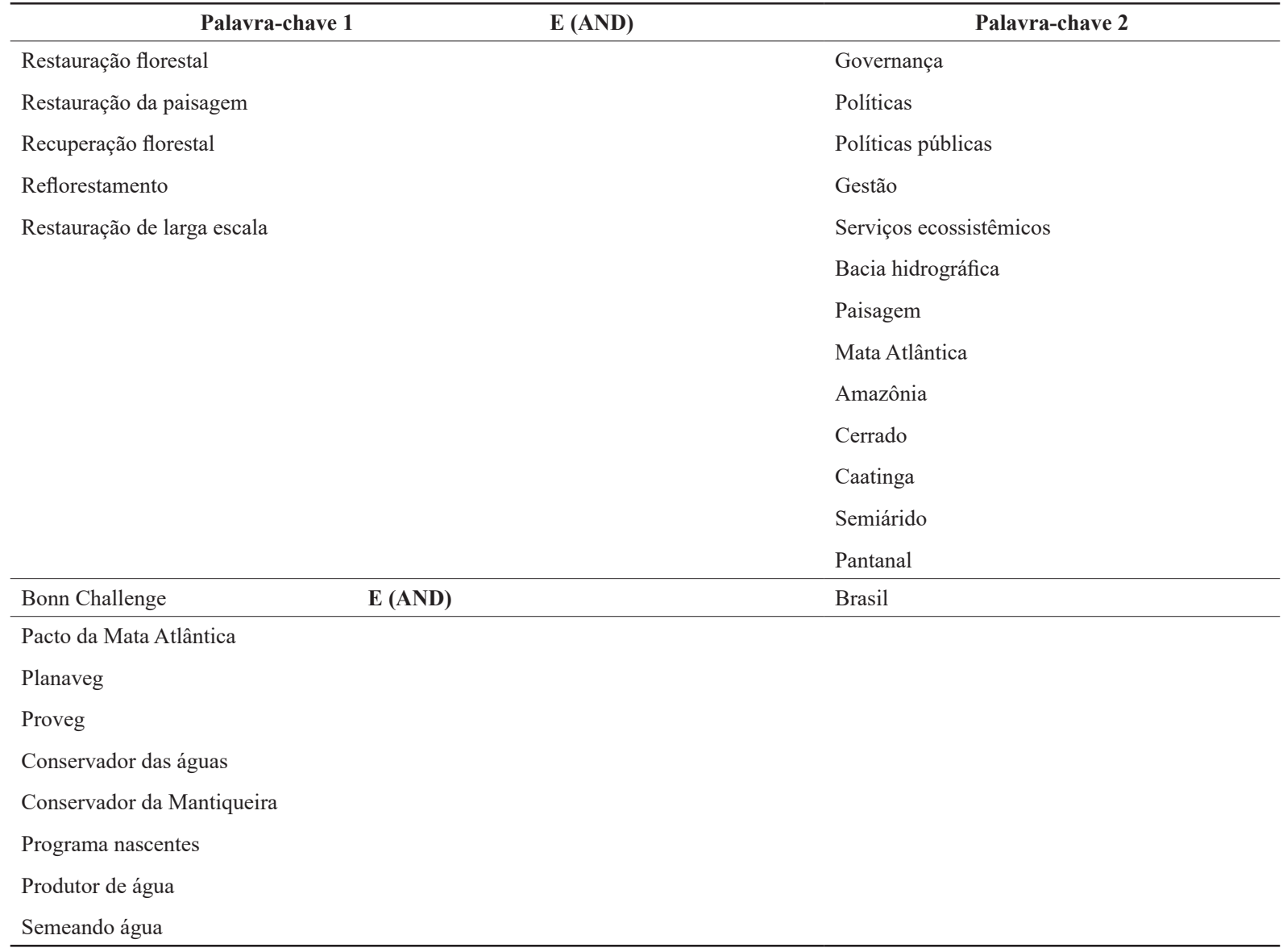


referências. Após a leitura completa de cada um dos artigos, mais 30 foram excluídos do banco de dados pelos mesmos critérios, restando 194 artigos.

Na segunda etapa, criou-se uma planilha para a extração de dados de cada um dos 194 artigos, contendo os dados bibliográficos e uma série de categorias de informação sobre a governança da RFP (Tabela 6). Essas categorias foram definidas a partir da leitura dos artigos de revisão, conceituais e teóricos sobre governança da restauração florestal levantados, além da literatura sobre governança de recursos comuns, e da expertise dos autores deste manuscrito.

A partir deste banco de dados foi feita uma análise quantitativa, cujos resultados são apresentados na Subseção 4.1. Um último filtro foi aplicado para selecionar apenas a literatura pertinente à RPF no Brasil, resultando em 147 referências bibliográficas, que foram utilizadas para uma análise qualitativa de iniciativas no país.

O método apresenta limitações, como a exclusão de trabalhos publicados antes de 2000 sobre o tema, e o foco na literatura acadêmica, que praticamente excluiu relatórios de órgãos governamentais e não governamentais. A seguir, são apresentados os resultados quantitativos e qualitativos da revisão da literatura.

\section{Resultados}

\subsection{Análise quantitativa da literatura}

Entre os artigos publicados (2000-2018), observa-se um incremento gradual no número de artigos/ano a partir de 2009, com um pico em 2016 (embora o levantamento de 2018 tenha sido encerrado antes do final do ano - Figura 1). A maior parte dos artigos publicados (59\%) tratou de estudos de casos, enquanto apenas $14 \%$ foram conceituais/teóricos, e 13\% revisões de literatura caso (Figura 2). A ênfase nos estudos de caso, que muitas vezes não trouxeram informações básicas sobre a governança da restauração no local investigado (como estrutura fundiária, usos da terra, etc.), é uma evidência de que a utilização arcabouços conceituais para auxiliar nos estudos de governança da RPF no Brasil ainda está em construção, como no restante do mundo.

TABELA 6 - Categorias utilizadas na extração de informações dos artigos levantados na literatura (n=194) e organização do banco de dados.

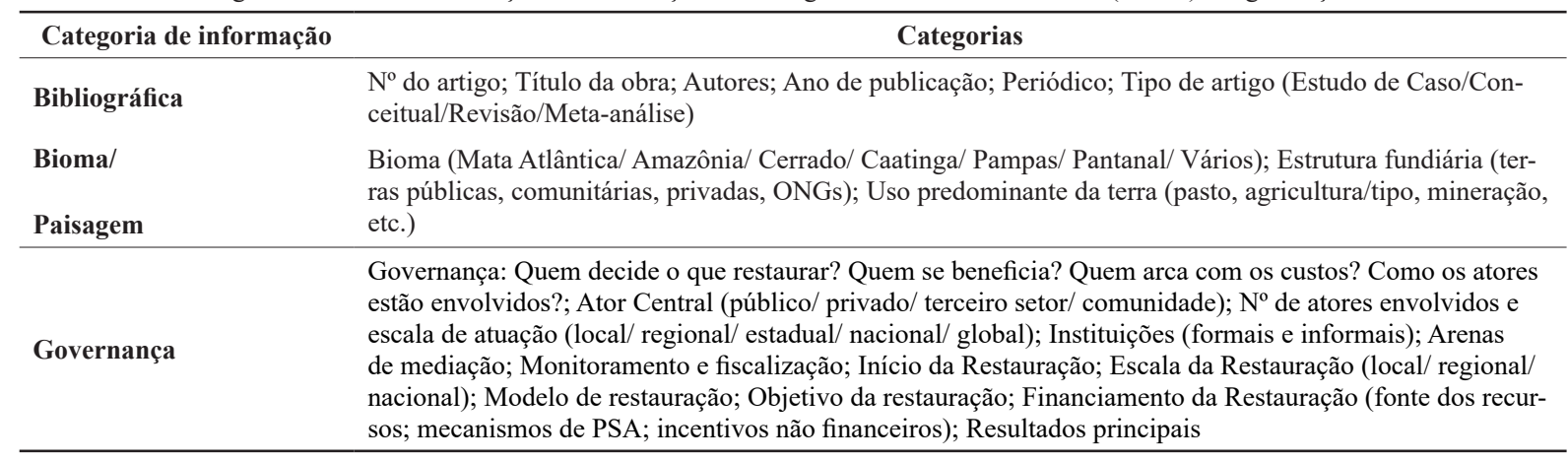




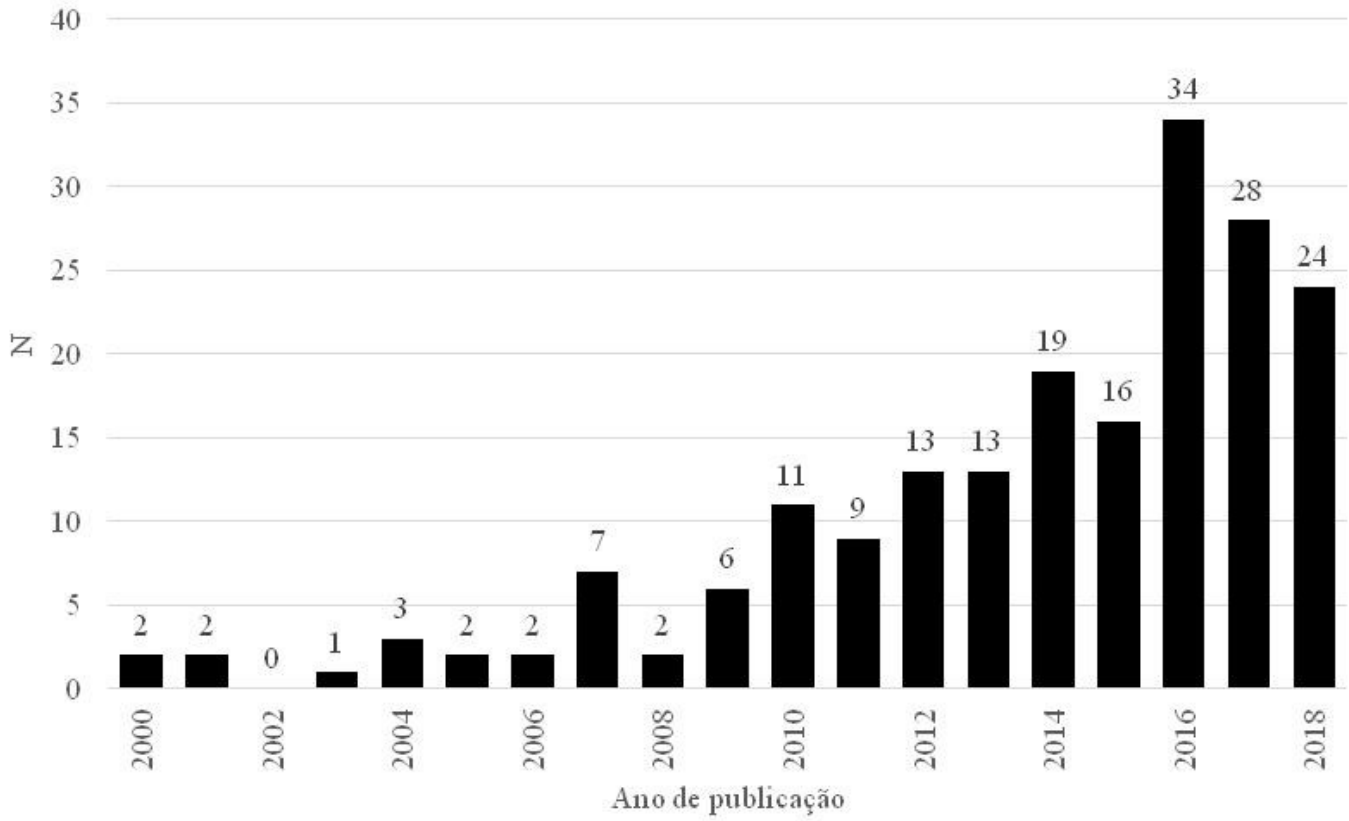

FIGURA 1 - Distribuição dos artigos sobre RFP levantados na literatura (2000-2018), por ano de publicação (n=194).

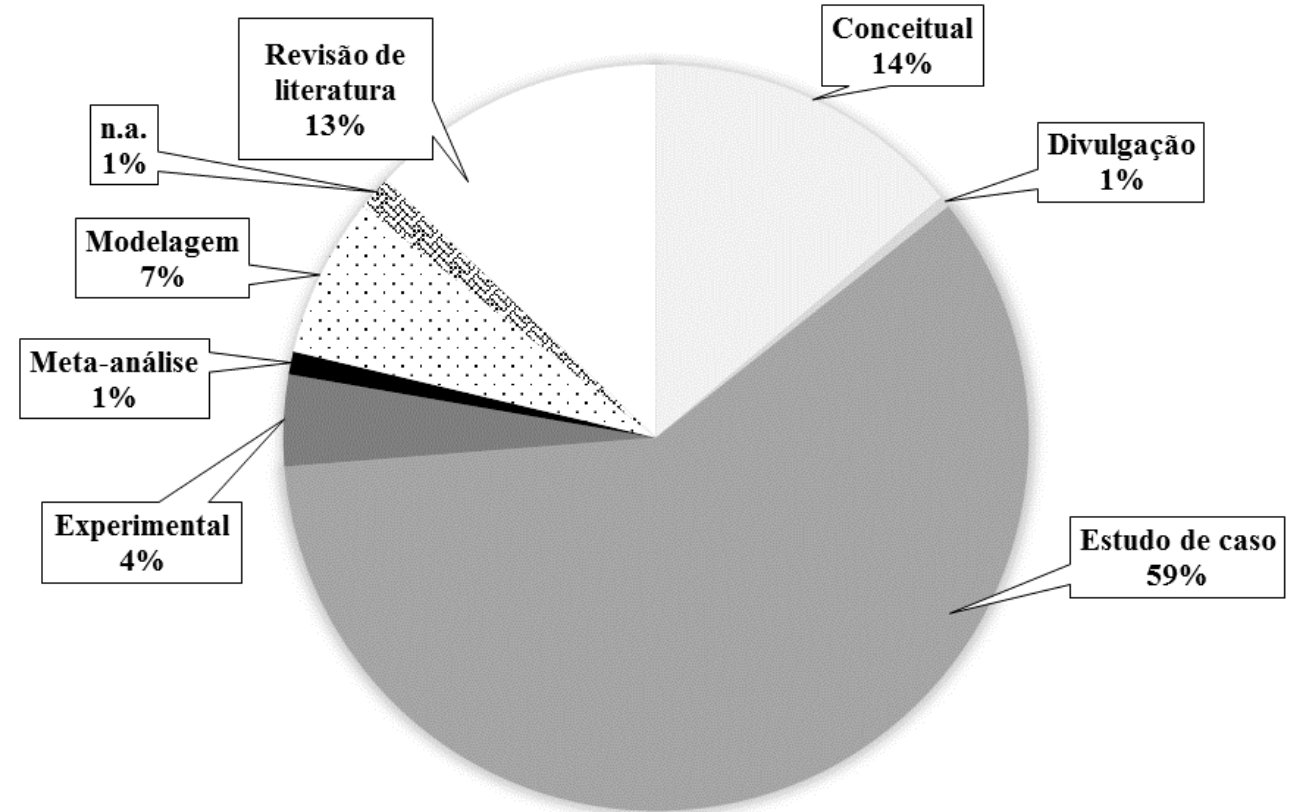

FIGURA 2 - Distribuição dos artigos sobre RFP levantados na literatura (2000-2018) segundo o tipo de publicação (n=194). 
Esta constatação de que há poucos trabalhos que investigam a governança da RFP é confirmada por van Oosten (2013), Guariguata \& Brancalion (2014), Ros-Tonen et al. (2014), Mansourian (2016; 2017) e Mansourian \& Sgard (2019). Do total de 194 artigos analisados, apenas 32\% (62) trouxeram algum tipo de informação sobre a governança da restauração florestal.

Os trabalhos que trataram da RFP na escala global somaram $15 \%(n=31)$ do total, enquanto que aqueles que consideraram o processo em florestas tropicais em todo o globo, não apenas no Brasil, somaram $10 \%(\mathrm{n}=21)$ dos artigos. Entre os biomas brasileiros tratados pelos artigos (cf. Ab' Saber,
2003), a Mata Atlântica teve o maior número de referências (48\%; $n=100)$ (Figura 3). Esta situação provavelmente reflete o grau de degradação/redução do bioma, a existência de fortes grupos de pesquisa em restauração florestal nos estados cobertos pelo bioma e a existência de uma importante rede de trabalho nesta escala de atuação - o Pacto pela Restauração da Mata Atlântica (Andrade et al., 2018). O movimento ambientalista envolvido com a conservação da Mata Atlântica permitiu, principalmente durante as décadas de 1980-1990, uma grande articulação de atores da sociedade civil e do Estado, gerando um capital social e participação em iniciativas de RFP. Os resultados da distribuição

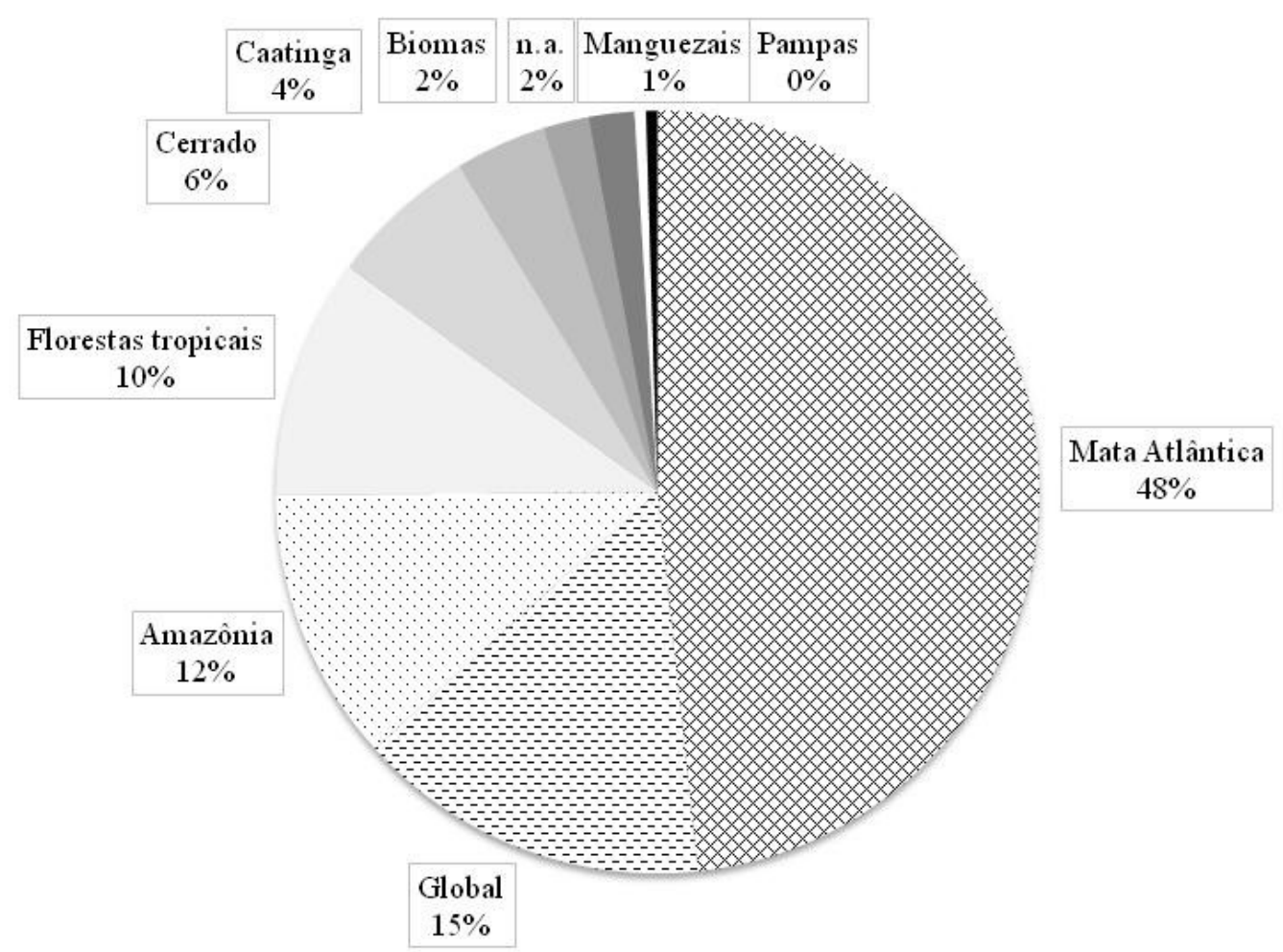

FIGURA 3 - Distribuição dos artigos sobre RFP levantados na literatura (2000-2018) segundo o tipo de bioma abordado (n=194). 
dos artigos por bioma apontam para a necessidade de direcionar recursos de pesquisa para os demais biomas brasileiros, alguns dos quais bastante ameaçados pelo avanço da fronteira agrícola, como a caatinga e o cerrado.

Do total analisado, $35 \%$ dos artigos trouxeram informações sobre a estrutura fundiária predominante da paisagem analisada (Figura 4), apontando que na maior parte dos casos a restauração está ocorrendo em paisagens com estruturas fundiárias mistas (13\%), seguidas por terras privadas (13\%) e terras públicas $(9 \%)$. Sobre o uso predominante da terra na paisagem, $64 \%$ dos artigos não trouxeram informação sobre o tema, $15 \%$ descrevem o uso como sendo diversificado (ex., urbano, silvicultura, ou vários usos em uma escala regional ou nacional), e em $9 \%$ cita-se a agropecuária (Figura 5).

\subsection{Análise qualitativa da literatura sobre governança da RFP no Brasil}

Do total de 147 artigos que tratam da RFP no Brasil, apenas 41 (28\%) trouxeram alguma informação sobre o tipo de governança, ou informações sobre quem decide o que restaurar, quem se beneficia, quem arca com os custos e como os atores estão envolvidos. Deste total, 63\% (26) avaliaram casos de governança com aspectos de colaboração entre os seus atores sociais, destacando-se seis iniciativas que representam diferentes modelos de governança (Tabela 7).

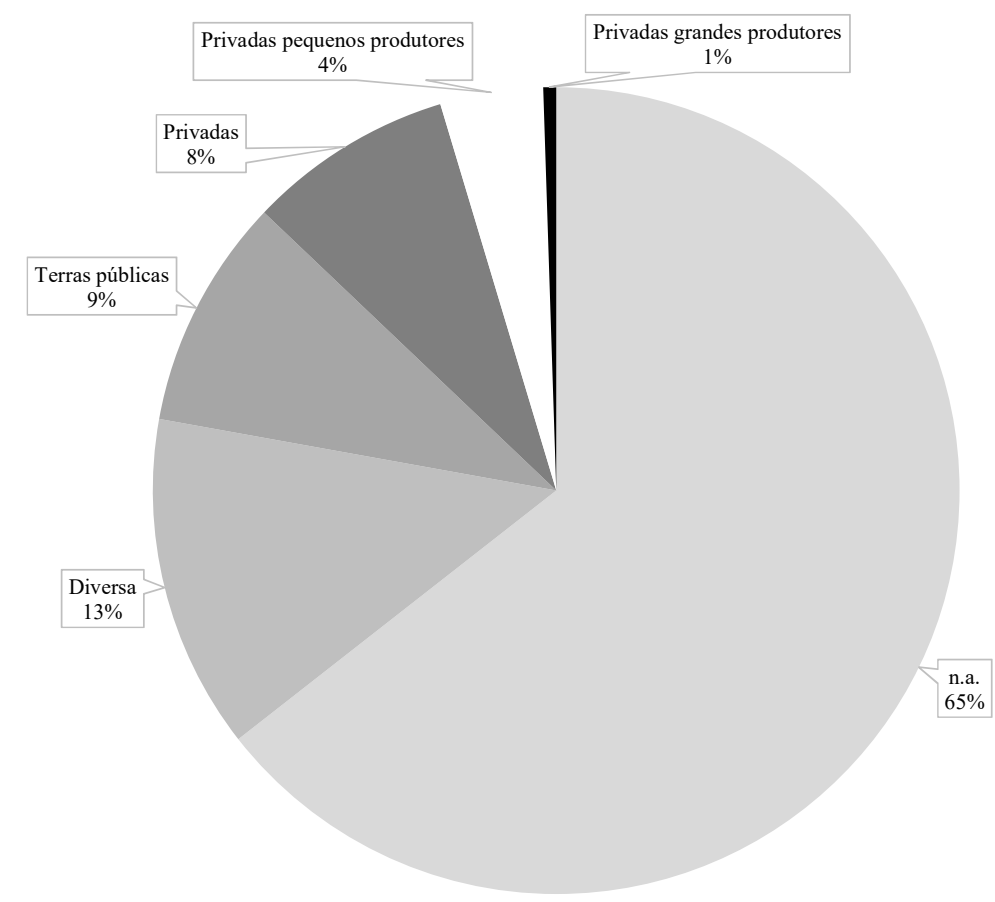




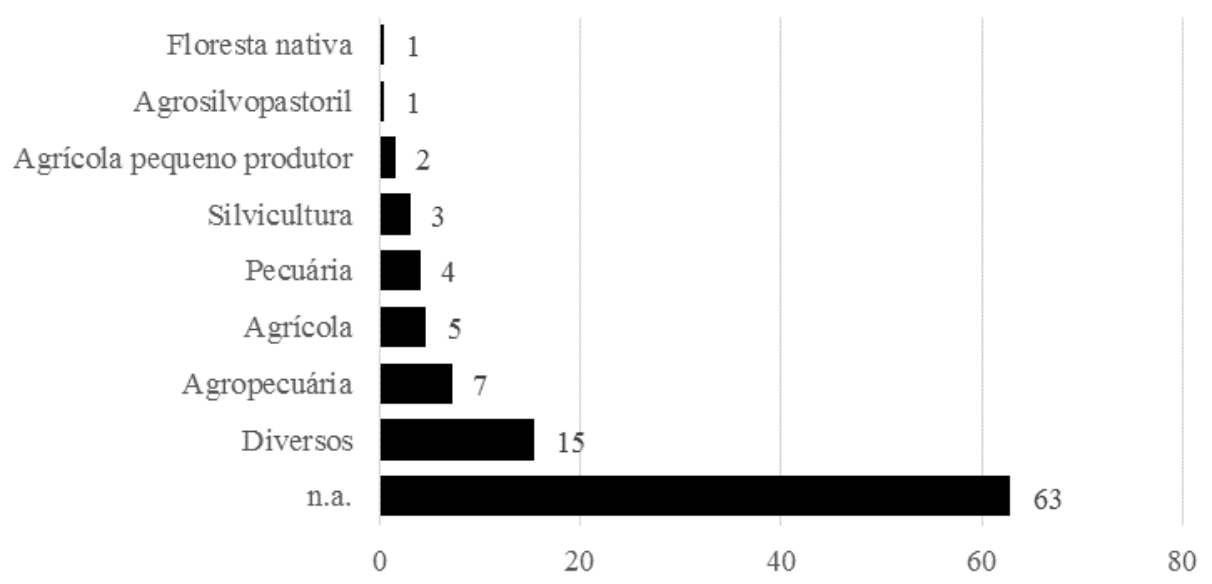

FIGURA 5 - Principais usos da terra nas paisagens submetidas a RFP segundo os artigos levantados na literatura, conforme informado pelos autores $(\mathrm{n}=194)$.

TABELA 7 - Diferentes modelos de governança da RFP apontados neste artigo para seis iniciativas brasileiras levantadas na literatura (20002018) $(n=41)$.

\begin{tabular}{|c|c|c|c|c|c|c|c|}
\hline \multirow[b]{2}{*}{ Iniciativas } & \multicolumn{7}{|c|}{ Modelos de Governança } \\
\hline & 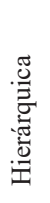 & 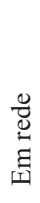 & 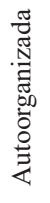 & 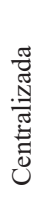 & 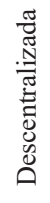 & 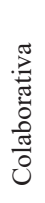 & 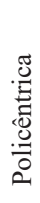 \\
\hline \multicolumn{8}{|l|}{ Pacto da Mata Atlântica (PMA) } \\
\hline \multicolumn{8}{|l|}{ Rede Brasileira de Restauração (REBRE) } \\
\hline \multicolumn{8}{|l|}{ Projeto de Recuperação de Matas Ciliares (PRMC, SP) } \\
\hline \multicolumn{8}{|l|}{ Programa de REDD+/PSA - Apuí (AM) } \\
\hline \multicolumn{8}{|l|}{ Conservador das Águas (MG) } \\
\hline Iniciativa Mata Atlântica nas RDS de Jacupiranga Barra do Turvo - SP & & & & & & & \\
\hline
\end{tabular}

Vieira et al. (2014) traçaram um panorama da governança da restauração florestal no Brasil e no estado do Pará (bioma Amazônia) e analisaram as instituições formais relacionadas à governança das florestas secundárias e da restauração. A partir disso, apontam as seguintes dificuldades: indefinição conceitual de termos técnicos (ex., restauração/ recuperação); falta de embasamento científico em normativas; incongruências entre os diferentes níveis da legislação, com obrigações ambientais de 
propriedades privadas distribuídas entre diplomas legais dos níveis federal, estadual e municipal; descontinuidade das gestões governamentais em processos que deveriam ser contínuos e de longo prazo e; constantes atualizações da legislação, causando dificuldades e insegurança jurídica. Os autores ( $o p$. cit.) ressaltam a importância dos atores-ponte que permitem conectar diversos setores (ex., agricultura e conservação) e níveis de governança, como o Programa Municípios Verdes do Pará ${ }^{2}$ Por fim, Vieira et al. (2014) apontam que existem problemas em vários dos fatores facilitadores da restauração previstos por Agrawal et al. (2008), Le et al. (2012) e Chazdon \& Guariguata (2016), dificultando o ganho de escala da RFP no Pará.

Por outro lado, duas iniciativas brasileiras de governança da RPF através da criação de redes de atores descentralizadas, multiníveis, estão alinhadas com os modelos apontados por Ball et al. (2014), Ros-Tonen et al. (2014) e Mansourian (2017): o Pacto da Mata Atlântica (PMA) e a Rede Brasileira de Restauração (REBRE). O PMA, tratado por vários dos artigos levantados (Calmon et al., 2011; Aronson \& Alexander, 2013; Andrade et al., 2018), reúne mais de 270 membros, que incluem ONGs, institutos e grupos de pesquisa, empresas privadas e órgãos governamentais, com o objetivo de promover um ganho de escala da RFP com a meta de restaurar 15 milhões de hectares de Mata Atlântica até 2050 (Melo et al., 2013, Brancalion et al., 2016).

O PMA caracteriza-se como um modelo de governança em rede, construído de baixo-para-cima (bottom-up) com o engajamento de múltiplos atores sociais. Sua gestão orienta-se por ações voltadas para a participação na formulação de políticas públicas, mobilização para financiamentos, geração e disseminação de conhecimento, capacitação e assistência técnica, e pesquisa para o desenvolvimento de novas tecnologias de RFP (Brancalion et al., 2016). O PMA destacou-se no debate sobre a reformulação do Código Florestal, no desenvolvimento do Plano Nacional para a Recuperação da Vegetação Nativa (PLANAVEG) e no apoio à Iniciativa para a Restauração da Mata Atlântica, com a mobilização de fundos para a RFP (Brancalion et al., 2016). Embora represente um exemplo positivo de governança, o PMA possui obstáculos a serem enfrentados, como a superação de barreiras legais e econômicas para a RFP; a adesão de proprietários rurais para a adequação legal de suas propriedades; o aperfeiçoamento da relação custo-benefício dos modelos de restauração (Aronson \& Alexander, 2013); e a concentração de membros e pesquisadores da região sudeste (Brancalion et al., 2016).

A REBRE, criada em 2010, representa outro modelo de governança da RFP, que funciona em rede e de forma descentralizada. Seu enfoque está na conexão de atores sociais da RFP de todo o país para a troca de conhecimento e experiências que contribuam para a ciência e a prática de restauração de ecossistemas. Em 2015, a REBRE criou um novo ente em sua estrutura, a Sociedade Brasileira de Restauração Ecológica (SOBRE), formalizada como organização não governamental (Isernhagen

\footnotetext{
2 “O Programa Municípios Verdes é um programa do Governo do Pará desenvolvido em parceria com municípios, sociedade civil, iniciativa privada, Instituto Brasileiro do Meio Ambiente e Recursos Naturais Renováveis (IBAMA) e Ministério Público Federal com o objetivo de combater o desmatamento no estado e fortalecer a produção rural sustentável por meio do ordenamento ambiental e fundiário e da gestão ambiental, com foco em pactos locais, monitoramento do desmatamento, implantação do Cadastro Ambiental Rural (CAR) e estruturação da gestão ambiental dos municípios participantes" (http://www.municipiosverdes.pa.gov.br/pages/quem_somos).
} 
et al., 2017). Ela tem o objetivo de treinar pessoas, sistematizar e divulgar informações sobre RFP e dar suporte à formulação de políticas públicas. Um aspecto da descentralização da REBRE está na sua estrutura de comunicação, que se dá por plataforma eletrônica na internet, que hospeda um blog, bibliografia e links para outros sites, além de outras redes sociais, como o Facebook (Isernhagen et al., 2017). Dentre os desafios de gestão da REBRE, destacam-se a melhoria de representação mais balanceada das diferentes regiões do país e a execução de mais encontros entre os membros para avançar na produção de conhecimento (Isernhagen et al., 2017).

No estado de São Paulo, o Projeto de Recuperação de Matas Ciliares (PRMC, 2005-2011), coordenado pela Secretaria do Meio Ambiente do Estado de São Paulo ${ }^{3}$ (SMA), financiado pelo GEF (Global Environment Facility Grant) e implementado pelo Banco Mundial, representa um modelo de governança da RFP hierárquico e centralizado pelo governo estadual. Os objetivos do PRMC compreendem o controle e reversão de processos de degradação dos solos em ecossistemas ripários e agroecossistemas adjacentes, através do manejo sustentável da terra e fortalecimento do arcabouço regulatório, por meio de políticas públicas. A área de atuação do PRMC inclui os territórios das bacias dos rios Paraíba do Sul, Piracicaba, Mogi-Guaçu e Tietê-Jacaré, onde 15 microbacias foram alvo de projetos de RFP, executados em parceria com outras organizações governamentais e ONGs (World Bank, 2014).
Os vários desafios dessa iniciativa incluem: $\mathrm{o}$ desinteresse dos produtores rurais devido à perda de área agricultável; a insuficiência de mecanismos de financiamento e as dificuldades para utilizar os recursos existentes; a falta de qualidade e de quantidade de sementes de espécies nativas; o baixo conhecimento sobre modelos de restauração de matas ciliares e a falta de instrumentos para integrar planejamento e monitoramento da restauração (World Bank 2014). Entre os resultados positivos, destacam-se a criação do Banco de Áreas para Recuperação Florestal; as normativas para a implementação de agroflorestas e coleta de sementes; a inclusão de PSA na Política Estadual de Mudanças Climáticas e; a criação de demanda induzida para projetos submetidos ao Fundo Estadual de Recursos Hídricos (FEHIDRO), em atendimento a linhas prioritárias estaduais definidas pelo Conselho Estadual de Recursos Hídricos, incluindo a recuperação de matas ciliares (World Bank, 2014).

Os Programas de REDD+ representam modelos de governança que se estabelecem no nível local, na relação direta com produtores rurais. Este é o caso da iniciativa implementada em um assentamento rural no município de Apuí (AM), para substituir os mecanismos de comando e controle (como a aplicação de sanções pela Lei de Proteção da Vegetação Nativa) por incentivos positivos para a RFP. Esses incentivos constituíram-se no PSA pela floresta em pé e pelas áreas restauradas (US\$ 47/ ha, durante os 30 anos do projeto), em substituição à pastagem extensiva. A iniciativa foi coordenada pelo Instituto para a Conservação e o Desenvolvimento (IDESAM), e contou com a participação de

${ }^{3}$ Atualmente Secretaria de Infraestrutura e Meio Ambiente - SIMA. 
outros órgãos públicos, sociedade civil e terceiro setor (Cenamo \& Carrero, 2012). Neste caso, a adesão ao PSA foi feita pela assinatura de Acordos de Conduta Ambiental e obediência à legislação ambiental, sob a pena de o produtor perder o título da terra, emitido pelo INCRA. O IDESAM ficou responsável pelo desenho de projeto, planejamento financeiro, execução, monitoramento anual, publicação dos dados on line, além de projetos de pesquisa sobre modelos de restauração e produção (Cenamo \& Carrero, 2012). A falta de regularização fundiária das propriedades e de conformidade com a legislação ambiental foram os principais gargalos apontados nesta iniciativa (Cenamo \& Carrero, 2012), que se caracteriza como um modelo de governança colaborativa em rede, centralizada pela coordenação do IDESAM e policêntrica.

Na Mata Atlântica, o programa de PSA de maior sucesso e reconhecimento internacional é o Conservador das Águas, desenvolvido pela Prefeitura de Extrema (MG) e em andamento desde 2007. Richards et al. (2015) apontam a importância da descentralização da gestão das bacias hidrográficas e criação de Comitês de Bacias como fatores institucionais essenciais para o desenvolvimento dessa iniciativa. Neste caso, o modelo de governança respaldado pela Política Nacional de Recursos Hídricos serviu como orientador para o desenvolvimento do Conservador das Águas, a partir do Programa Produtor de Água. Criado pela Agência Nacional das Águas (ANA), o Programa Produtor de Água abrigou projetos realizados no âmbito de bacias hidrográficas. No caso do Conservador das Águas, a Prefeitura de Extrema foi pioneira em institucionalizar o seu Fundo Municipal para Pagamento de Serviços Ambientais, criado em 2009 para atuar até 2030. Esse fundo foi beneficiado pela arreca- dação de impostos municipais oriundos do parque industrial instalado no município e incentivado pela combinação da proximidade do município com o estado de São Paulo e dos impostos mais baixos taxados em Minas Gerais.

O Fundo Municipal para Pagamento de Serviços Ambientais é usado para financiar os produtores rurais que adiram ao Cadastro Ambiental Rural (CAR) e, voluntariamente, restaurem as matas ciliares. Para isso, criou-se um arcabouço legal para autorizar a captação de recursos financeiros com parceiros externos e a elaboração de contratos com os proprietários (Richards et al., 2015). O sistema de monitoramento é executado por vários parceiros e está baseado em indicadores de quantidade e qualidade das águas das sub-bacias atendidas, além de redução de erosão e sequestro de carbono.

$\mathrm{Na}$ avaliação de Richards et al. (2015), a conjunção entre a atuação de organizações municipais, pressões socioeconômicas e o cumprimento de legislação ambiental (especificamente, o novo Código Florestal) motivou a implementação do Conservador das Águas de um lado, e forçou a adesão do produtor rural, do outro. As relações estabelecidas entre o poder público municipal e outras organizações da sociedade civil permitiram resolver problemas de financiamento e de conhecimento técnico, o que foi garantido pela estabilidade do governo municipal, que reelegeu o mesmo partido e pode manter os seus técnicos municipais. Este caso ilustra um modelo de governança concebido para atuar no nível municipal, de forma centralizada na Prefeitura Municipal, mas que se avança pela colaboração com múltiplos parceiros, como a organização não governamental The Nature Conservancy (TNC).

Ball et al. (2014) avaliaram uma iniciativa de RFP com múltiplos atores no Vale do Ribeira 
(Barra do Turvo, SP), coordenada por uma ONG internacional em parceria com a SMA, financiada pelo Banco Nacional de Desenvolvimento Econômico e Social (BNDES, Iniciativa Mata Atlântica), e executada em duas Reservas de Desenvolvimento Sustentável do Mosaico de Jacupiranga. Os modelos de restauração foram desenvolvidos por moradores caiçaras e quilombolas, organizados em associações locais, em conjunto com a Universidade de São Paulo. A ONG se responsabilizou pela manutenção do projeto pelos dois primeiros anos, pagamento de diárias aos produtores locais e assistência técnica. Entre os gargalos da governança do projeto, os autores ressaltam a complexidade legal ${ }^{4} \mathrm{e}$ fundiária para o desenvolvimento do projeto, e a insegurança jurídica sobre mudanças futuras na legislação (em particular, a Lei de Vegetação Nativa). Esta insegurança jurídica incide sobre o risco de perda de retorno econômico futuro das áreas restauradas. Outro gargalo identificado se refere à assimetria de poder entre a ONG gestora e as associações locais.

\section{Considerações finais}

Os dados sobre a RFP no Brasil mostram que o país está avançando no desenvolvimento da governança da RFP, principalmente na Mata Atlântica e na Amazônia, o que ficou demonstrado por meio de publicações que exploram o tema por meio de estudos de caso. As iniciativas descritas neste estudo salientam o aspecto da colaboração presente em todas elas (Tabela 7), o que confirma a relevância do papel de parceiros e organizações-ponte em ações de comunicação, apoio técnico e financeiro e nos esforços de integração entre setores distintos, como a agropecuária e a conservação de florestas.

Os exemplos do Programa Conservador das Águas, em nível municipal, e do PRMC, no estado de São Paulo, indicam a importância de municípios e estados em estabelecer arranjos institucionais que contemplem as dimensões ecológica, social e econômico-financeira da RFP, em uma abordagem integrada na paisagem. O Conservador das Águas tem sido uma referência para outros municípios em como implementar um projeto de longo prazo com financiamento contínuo e formação de um fundo autônomo e municipal de PSA. Já no nível estadual, o PRMC tem no Banco de Áreas para a Restauração Florestal um modelo de gestão de oportunidades para a RFP no estado de São Paulo. Apesar dos aspectos promissores, vale ressaltar que ambas as iniciativas se caracterizam por gestões centralizadas em apenas um ente público, sugerindo a necessidade de se desenvolver estruturas policêntricas de governança que ampliem a sua capacidade adaptativa no longo prazo. $\mathrm{O}$ atual contexto de desmonte da governança ambiental do país serve de alerta para a fragilidade de sistemas centrados no Estado (Adams et al. 2020, Barbosa et al. 2021).

Nesse sentido, os arranjos institucionais em redes descentralizadas, representadas pelo PMA e REBRE, merecem destaque como modelos inovadores de governança da RFP no Brasil, como sistemas não hierárquicos, com múltiplos atores e ações que abordam temas amplos e transversais, como a conservação ambiental, a formação de pessoas e o suporte à formulação de políticas públicas.

${ }^{4}$ Principais leis: novo Código Florestal, Lei da Mata Atlântica, SNUC, legislação sobre manejo e comercialização de espécies nativas ameaçadas (ex. Euterpe edulis). 
São muitos os desafios a serem tratados para que se avance na governança da RFP, que vão desde a falta de financiamentos contínuos de longo prazo, a complexidade da legislação florestal que causa insegurança jurídica, a indefinição de regularização fundiária, o desinteresse de proprietários de imóveis rurais sobre o tema e a insuficiência de acesso à informação sobre RFP. Quanto às oportunidades, a existência de um arcabouço institucional consistente representa um alicerce representativo para o desenvolvimento de sistemas de governança nos níveis sociopolíticos e no nível da paisagem.

Ao analisar o estado de conhecimento dos modelos conceituais de governança da RFP e como esses modelos se aplicam a iniciativas brasileiras, evidencia-se a carência de estudos específicos com enfoque sobre a governança da RFP no Brasil. Esta lacuna de pesquisa mostra-se como uma oportunidade não somente no âmbito das Universidades e Institutos de Pesquisa, mas também nas redes formais, como o PMA e REBRE, e redes de colaboração que se formam a partir do desenvolvimento de programas e projetos de RFP. O desenvolvimento de pesquisas nessa área, e o trabalho feito por inúmeras ONGs que atuam em campo, produzem um corpo de conhecimento valioso que pode alimentar redes de aprendizados capazes de contribuir para a evolução e aperfeiçoamento dos arranjos de governança da RFP no Brasil.

\section{Agradecimentos}

Os autores agradecem ao World Resources Institute - WRI Brasil pelo financiamento do Projeto "Maximizando Oportunidades Econômicas em Escala para a Restauração de Paisagens e Florestas no
Brasil - Pró Restaura", do qual este estudo é parte, e em especial à Mariana Oliveira. Os coautores JRB, GSSRM e VHS agradecem ao WRI Brasil e à $\mathrm{CAPES} / \mathrm{CNPq}$ pelas bolsas de complementação - Nível BC-D para JRB e GSSRM, e Nível BC-M para VHS. C. Adams agradece ao Instituto de Energia e Ambiente (IEE) e à Escola de Artes, Ciências e Humanidades (EACH) da Universidade de São Paulo (USP) pelo apoio acadêmico. C. Futemma agradece ao Núcleo de Estudos e Pesquisas Ambientais (NEPAM) da Universidade Estadual de Campinas (UNICAMP) e ao Programa de Doutorado Ambiente e Sociedade do NEPAM/ UNICAMP pelo apoio acadêmico e logístico. E por fim, os autores agradecem a Aurélio Padovezi por ter acreditado neste trabalho.

\section{Referências}

Ab'Saber, A. N. Os domínios de natureza no Brasil: potencialidades paisagísticas. São Paulo: Ateliê Editorial, 2003.

Adams, C.; Borges, Z.; Moretto, E. M.; Futemma, C. Governança Ambiental no Brasil: Acelerando em Direção aos Objetivos de Desenvolvimento Sustentável ou Olhando pelo Retrovisor? Cadernos Gestão Pública e Cidadania, 25(81), 1-13, 2020.

Agrawal, A.; Chhatre, A.; Hardin, R. Changing Governance of the World's Forests. Science, 320, 1460-1462, 2008.

Alexander, S.; Nelson, C.R.; Aronson, J.; Lamb, D.; Cliquet, N.; Erwin, K.L.; Finlayson, C.M.; De Groot, R.S.; Harris, J.A.; Higgs, E.S.; Hobbs, R.J.; Robin, R.R.; Lewis I.R.; Martinez, D.; Murcia, C. Opportunities and Challenges for Ecological Restoration within REDD+. Restoration Ecology, 19(6), 683-668, 2011.

Andrade, A.; Bargos, D.C.; Fialho, T.M.; Cristofaro, S. Desafios da cadeia da restauração florestal no Vale do Paraíba Paulista. Sociedade e Natureza, 30(3), 257-277, 2018. 
Aronson, J.; Alexander, S. Steering Towards Sustainability Requires More Ecological Restoration. Natureza \& Conservação, 11(2), 127-137, 2013.

Arts, B.; Visseren-Hamakers, I. Forest governance: a state of the art review. In: Arts, B.; van Bommel, S.; et al. (Eds.). Forest-People Interfaces. Wageningen: Wageningen Academic Publ., 2012. p. 241-257.

Ball, A.A.; Gouzerh, A.; Brancalion, P. H. S. Multi-Scalar Governance for Restoring the Brazilian Atlantic Forest: A Case Study on Small Landholdings in Protected Areas of Sustainable Development. Forests, 5, 599-619, 2014.

Banco Mundial. BioCarbon Fund Launches $\$ 280$ Million Initiative for Sustainable Forest Landscapes, 2013. Disponível em: <http://www.worldbank.org/en/news/ feature/2013/11/20/biocarbon-fund-initiative-promote-sustainable-forest-landscapes>. Acesso em: mar. 2019.

Barbosa, L. M.; Alves, M. A. S.; Grelle, C. E. V. Actions against Sustainability: Dismantling of the Environmental Policies in Brazil. Land Use Policy, 104, 105384, 2021.

Brancalion, P.H.S.; Pinto, S.R.; Pugliese, L.; Padovezi, A.; Rodrigues, R.R.; Calmon, M.; Carrascosa, H.; Castro, P.; Mesquita, B. Governance innovations from a multi-stakeholder coalition to implement large-scale Forest Restoration in Brazil. World Development Perspectives, 3, 15-17, 2016.

Brondízio, E.S.; Ostrom, E.; Young, O.R. Connectivity and the Governance of Multilevel Social-Ecological Systems: The Role of Social Capital. Annual Review of Environment and Resources, 34, 253-278, 2009.

Butler, W.H.; Goldstein, B.E. The US Fire Learning Network: springing a rigidity trap through multiscalar collaborative networks. Ecology and Society, 15(3), 21, 2010.

Butler, W.H.; Monroe, A.E.; Mccaffrey, S. Collaborative Implementation for Ecological Restoration on US Public Lands: Implications for Legal Context, Accountability, and Adaptive Management. Environmental Management, 55, 564-577, 2015.

Calmon, M.; Brancalion, P.H.S.; Paese, A.; Aronson, J.; Castro, P.; Da Silva, S.C.; Rodrigues, R.R. Emerging Threats and Opportunities for Large-Scale Ecological Restoration in the Atlantic Forest of Brazil. Restoration Ecology, 19(2),
154-158, 2011.

Cameron, A. Restoration of Ecosystems and Ecosystem Services. In: Schreckenberg, K.; Mace, G.; Poudyal, M. (Eds.). Ecosystem Services and Poverty Alleviation. Tradeoffs and Governance. London: Routledge, 2018. p. 142-156.

Cash, D.W.; Adger, W.; Berkes, F.; Garden, P.; Lebel, L.; Olsson, P.; Pritchard, L.; Young, O. Scale and cross-scale dynamics: governance and information in a multilevel world. Ecology and Society, 11(2), 8, 2006.

Cenamo, M.C.; Carrero, G.C. Reducing Emissions from Deforestation and Forest Degradation (REDD) in Apuí, Southern Amazonas: Challenges and Caveats Related to Land Tenure and Governance in the Brazilian Amazon. Journal of Sustainable Forestry, 31(4-5), 445-468, 2012.

Chazdon, R.L.; Brancalion, P.H.S.; Laestadius, L.; Bennett-Curry, A.; Buckingham, K.; Kumar, C.; Moll-Rocek, J.; Vieira, I.C. Guimarães; W., Sarah, J. When is a forest a forest? Forest concepts and definitions in the era of forest and landscape restoration. Ambio, 45, 538-550, 2016.

Chazdon, R.L.; Guariguata, M.R. Natural regeneration as a tool for large-scale forest restoration in the tropics: prospects and challenges. Biotropica, 48(6), 716-730, 2016.

Chazdon, R.L.; Gutierrez, V.; Brancalion, P.H.S.; Laestadius, L.; Guariguata, M.R. Co-Creating Conceptual and Working Frameworks for Implementing Forest and Landscape Restoration Based on Core Principles. Forests, 11, 706, 2020.

Davoudi, S.; Evans, N.; Governa, F.; Santangelo, M. Territorial governance in the making approaches, methodologies, practices. Boletín de la A.G.E, 46, 351-355, 2008.

Diver, S. Co-management as a Catalyst: Pathways to Post-colonial Forestry in the Klamath Basin, California. Human Ecology, 44, 533-546, 2016.

Fisher, A.P. Forest landscapes as social-ecological systems and implications for management. Landscape and Urban Planning, 177, 138-147, 2018.

Folke, C.; Hahn, T.; Olsson, P. Norberg, J. Adaptive Governance of Social-Ecological Systems. Annual Review of Environment and Resources, 30, 441-73, 2005. 
Gibson, C.C.; Ostrom, E.; Ahn T.K. The concept of scale and the human dimensions of global change: a survey. Ecological Economics, 32, 217-239, 2000.

Guariguata, M.R.; Brancalion, P.H.S. Current Challenges and Perspectives for Governing Forest Restoration. Forests, 5, 3022-3030, 2014.

IPBES - Intergovernmental Science-Policy Platform on Biodiversity and Ecosystem Services. Summary for policymakers of the assessment report on land degradation and restoration of the Intergovernmental Science-Policy Platform on Biodiversity and Ecosystem Services. R. Scholes, L. Montanarella, A. Brainich, N. Barger, B. ten Brink, M. Cantele, B. Erasmus, J. Fisher, T. Gardner, T. G. Holland, F. Kohler, J. S. Kotiaho, G. Von Maltitz, G. Nangendo, R. Pandit, J. Parrotta, M. D. Potts, S. Prince, M. Sankaran and L. Willemen (Eds.).Bonn, Germany: IPBES Secretariat, 2018.

Isernhagen, I.; Moraes, L.F.D.; Engel, V.L. The rise of the Brazilian Network for Ecological Restoration (REBRE): what Brazilian restorationists have learned from networking. Restoration Ecology, 25(2), 172-177, 2017.

IUCN - International Union for Conservation of Nature e WRI - World Resources Institute. Guia sobre a Metodologia de Avaliação de Oportunidades de Restauração (ROAM): Avaliação de oportunidades de restauração de paisagens florestais em nível subnacional ou nacional. Documento de trabalho (Edição-teste). Gland: IUCN, 2014.

James, K.L.; Randall, N.P.; Haddaway, N.R. A methodology for systematic mapping in environmental sciences. Environmental Evidence, 5, 7-, 2016.

Le H.D.; Smith C.; Herbohn J.; Harrison, S. More than just trees: Assessing reforestation success in tropical developing countries. Journal of Rural Studies, 28, 5-19, 2012.

Locatelli, B.; Catterall, C.P.; Imbach, P.; Kumar, C.; Lasco, R.; Marín-Spiotta, E.; Mercer, B.; Powers, J.S.; Schwartz, N.; Uriarte, M. Tropical reforestation and climate change: beyond carbon. Restoration Ecology, 23(4), 337-343, 2015.

Long, H., Liu, J. Tu, C. e Fu, Y. From State-controlled to Polycentric Governance in Forest Landscape Restoration: The Case of the Ecological Forest Purchase Program in Yong'an Municipality of China. Environmental Management, 62(1), 58-69, 2018.
Maginnis, S.; Jackson, W. Restoring Forest landscapes: Forest landscape restoration aims to re-establish ecological integrity and enhance human well-being in degraded forest landscapes. Gland: IUCN - The World Conservation Union, 2002.

Mansourian, S. Understanding the Relationship between Governance and Forest Landscape Restoration. Conservation and Society, 14(3), 267-278, 2016.

Mansourian, S. Governance and forest landscape restoration: A framework to support decision-making. Journal for Nature Conservation, 37, 21-30, 2017.

Mansourian, S.; Parrotta, J.; Balaji P.; Bellwood-Howard, I.; Bhasme, S.; Bixler, R.P.; Boedhihartono, A.K.; Carmenta, R.; Jedd, T.; de Jong, W.; Lake, F.K.; Latawiec, A.; Lippe, M.; Rai, N.D.; Sayer, J.; Dexter, K.V.; Vira; B.; Visseren-Hamakers, I.; Wyborn, C.; Yang, A. Putting the pieces together: Integration for forest landscape restoration implementation. Land Degradation and Development, 31(4), 419-429, 2019.

Mansourian, S.; Sgard, A. Diverse interpretations of governance and their relevance to forest landscape restoration. Land Use Policy, 104, 104011, 2019.

Melo, F.P.L.; Pinto, S.R.R.; Brancalion, P.H.S.; Castro, P.S.; Rodrigues, R.R.; Aronson, A.; Tabarelli, M. Priority setting for scaling-up tropical forest restoration projects: Early lessons from the Atlantic Forest Restoration Pact. Environmental Science \& Policy, 33, 395-4004, 2013.

Nagendra, H.; Ostrom, E. Polycentric governance of multifunctional forested landscapes. International Journal of the Commons, 6(2), 104-133, 2012.

Pistorius, T.; Freiberg, H. From Target to Implementation: Perspectives for the International Governance of Forest Landscape Restoration. Forests, 5, 482-497, 2014.

Reyes-García, V.; Fernández-Llamazares, A.; Mcelwee, P.; Molnár, Z.; Öllerer, K.; Wilson, S.J.; Brondizio, E.S. The contributions of Indigenous Peoples and local communities to ecological restoration. Restoration Ecology, 27(1), 3-8, 2019.

Richards, R.C.; Rerolle, J.; Aronson, J.; Pereira, P.H.; Gonçalves, H.; Brancalion, P.H.S. Governing a pioneer program on payment for watershed services: Stakeholder 
involvement, legal frameworks and early lessons from the Atlantic forest of Brazil. Ecosystem Services, 16, 23-32, 2015.

Ros-Tonen, M.; Derkyi, M.; Insaidoo, T.F.G. From Co-Management to Landscape Governance: Whither Ghana's Modified Taungya System? Forests, 5, 2996-3021, 2014.

Seixas, C.S.; Berkes, F. Community-based enterprises: the significance of partnership and institutional linkages. International Journal of the Commons, 4(1), 183-212, 2010.

Skutsch, M.; Turnhout, E. How REDD is performing communities. Forests, 9(10), 638-659, 2018.

van Oosten, C. Restoring Landscapes - Governing Place: A Learning Approach to Forest Landscape Restoration. Journal of Sustainable Forestry, 32(7), 659-676, 2013.
Vieira, I.C.G.; Gardner, T.; Ferreira, J.; Lees, A.C.; Barlow, J. Challenges of Governing Second-Growth Forests: A Case Study from the Brazilian Amazonian State of Pará. Forests, 5, 1737-1752, 2014.

World Bank. Project performance assessment report, Brazil. Ecosystem restoration of riparian forests in São Paulo (TF55091). Washington: World Bank, Report N87105, 2014.

Young, K.R., Lipton, J.K. Adaptive Governance and Climate Change in the Tropical Highlands of Western South America. Climatic Change, 78, 63-102, 2006.

Young, O. Vertical interplay among scale dependent environmental and resource regimes. Ecology and Society, 11(1), 27, 2006. 